parcerias que estamos construindo só se tornarão permanentes quando um parceiro amar e respeitar as diferenças do outro. Ver a si e ver o outro.

Completando cinco anos de atividades do UNI-Botucatu, é importante ressaltar, nesta oportunidade, a mudança nas relações entre a Universidade, os serviços de saúde e a comunidade. É o trabalho solidário e a parceria permanente que nesses anos superaram a articulação restrita dos dirigentes das instituições, criando uma articulação coletiva envolvendo professores, estudantes, profissionais dos serviços de saúde e membros da comunidade.

Parceiros do UNI-Botucatu, enfrentamos grandes apostas como a concretização da Reforma Curricular do Curso de Medicina, a entrada do Curso de Enfermagem em programas na rede, a utilização das unidades básicas de saúde, do Ambulatório Regional de Especialidades, de creches e escolas como novos cenários de ensino, a implantação do Programa de Saúde da Mulher no Hospital Sorocabana, a implantação dos Conselhos de Unidade da Saúde em quase todos os Centros de Saúde do Município, a realização de uma grande Conferência Municipal de Saúde e a própria criação da Fundação UNI-Botucatu. Ganhamos essas apostas, porque o trabalho foi coletivo...

José Lúcio Martins Machado, Fundação UNI-Botucatu. Faculdade de Medicina de Botucatu - UNESP.

\section{OUTRAS LEITURAS DA \\ REALIDADE: \\ alfabetização de adultos pela educação em saúde}

O presente trabalho, desenvolvido por estudantes da Faculdade de Medicina de Botucatu da Universidade Estadual Paulista (UNESP), foi orientado por docentes dos departamentos de Saúde Pública e de Educação da UNESP/Campus Botucatu. Surgiu por iniciativa de aproximadamente 10 acadêmicos do $3^{\circ}$ ano do curso médico, motivados pelo interesse de vivenciarem diferentes formas de interação com a comunidade. Teve início em 1993, com um ciclo de palestras sobre temas de saúde, ministrado aos sábados, para cerca de 15 mulheres que participavam de um grupo de artesanato ligado ao Centro de Saúde do bairro Jardim Peabirú na cidade de Botucatu. A preocupação inicial era a de trabalhar com conhecimentos da área da Saúde, julgados por esses estudantes como importantes para a comunidade. Essa primeira etapa despertou algumas necessidades no grupo de mulheres entre elas a de exercerem uma participação mais efetiva no processo. Nesse momento a população expressa, então, sua vontade de ser alfabetizada.

O projeto ganhou, assim, outro rumo e os estudantes de medicina buscaram formas alternativas de ensinar e aprender com a população, buscando em Paulo Freire e Emília 
Ferreiro, o embasamento teórico-metodológico. Essa proposta deu início a um processo pedagógico voltado para a formação dos dois pólos (professores e alunos), ambos sujeitos do processo em que estavam inseridos, tendo como preocupação fundamental a busca de uma relação dialógica.

A percepção de que os homens não são seres vazios, simples receptores de informações, mas indivíduos que trazem experiências e conhecimentos e são capazes de superar seus próprios limites, assumindo posturas críticas e conscientes quando desafiados e problematizados em suas relações com o mundo, foi balizando caminhos $e$ demarcando os desafios metodológicos para uma prática dialógica com a comunidade. Neste processo de trabalhar "com" a população e não "para a" população, algumas reflexões foram construídas, apontando para os estudantes de medicina a necessidade de perceberem o quanto a questão do Analfabetismo se constitui como limite para o exercício da cidadania, na medida em que dificulta a apropriação de conhecimentos, o acesso à informação $e$ às possibilidades de comunicação e expressão.

$\mathrm{Na}$ área de saúde, essa dificuldade de apropriação de conhecimento pode resultar em destituição da população de seus direitos de conhecer acerca de sua saúde, de sua doença e do seu tratamento, estabelecendo-se um cenário que possibilita o exercício de uma prática autoritária, favorecida por uma atitude de submissão da população. Esses fatos aparecem como fatores que colaboram para a expropriação da população no que se refere a seu processo de saúde.

A busca de uma prática democrática de educação em saúde e a vivência junto à comunidade, possibilitou aos estudantes de medicina perceberem o quanto sua formação médica, apoiada numa concepção disciplinar, fornece-lhes uma visão compartimentada $e$ restrita do corpo e da doença, com ênfase principalmente em conteúdos técnicos. Além disso, permitiu observar a tendência à desvalorização de conteúdos éticos e humanísticos nas relações entre profissionais de saúde-pacientes. Relações nas que o profissional de saúde, como reprodutor de verdades científicas, legitima, perante a comunidade, os valores dominantes, que situam como a principal causa dos problemas de saúde a conduta de quem sofre a problemática. (Garcia, ${ }^{1}$ 1994)

A experiência com a comunidade permitiu perceber que as relações na área de saúde, principalmente aquelas entre profissional de saúde e paciente, se dão dentro de um contexto muitas vezes autoritário, seguindo o Modelo de Comunicação "Unilinear", descrito por Teixeira² (1997), em que o sujeito emite

\footnotetext{
${ }^{1}$ GARCIA, E. B. Razón y Poder en el discurso educativo en Salud. Palestra apresentada no CONGRESSO MUNDIAL DE MEDICINA SOCIAL, 8. Guadalajara, México, 1994.

2 TEIXEIRA, R.R. - Modelos Comunicacionais e Práticas de Saúde. Interface - Comunicação, Saúde, Educação, v.1, n. 1, 1997, p.7-40.
} 
a mensagem para o outro pólo que, na condição de mero receptor da mensagem, é transformado em simples objeto dentro deste processo comunicacional.

Paralelamente ao desenvolvimento dessas reflexões pelos estudantes de medicina, estruturou-se um Plano de Ação para trabalhar a questão da alfabetização, procurando-se organizar aulas capazes de integrar a saúde no cotidiano da população. As aulas, elaboradas de forma a possibilitar as inter-relações entre professores /alunos / objeto de conhecimento, procuraram valorizar o processo de construção de conhecimento pelo coletivo do grupo, apoiando-se em uma concepção ética de respeito ao outro. Foram organizadas $e$ estruturadas com atividades de leitura, interpretação e discussão de textos retirados de jornais e revistas. Alguns destes textos foram elaborados pelos professores (estudantes de medicina) mediante pesquisas. Além da questão da Saúde, foram trabalhados temas de valorização cultural e artística, questões sociais e políticas. $\mathrm{O}$ trabalho em sala de aula procurou organizarse com base na idéia de "temas geradores", descrita por Paulo Freire. Estes temas, retirados do próprio cotidiano dos alfabetizandos, objetivaram uma nova leitura do mundo pela problematização e discussão coletiva, procurando possibilitar o conhecimento consciente e crítico, que pode libertar os homens de situações opressoras. O trabalho envolveu, assim, a população $e$ estudantes universitários. Os alunos alfabetizandos, na sua maioria, pessoas do sexo feminino com faixa etária acima de 50 anos, eram ex-lavradores e trabalhadores rurais moradores do bairro Jardim Peabirú localizado na periferia de Botucatu. O grupo de alfabetizadores, constituído por 5 estudantes de graduação da Faculdade de Medicina de Botucatu (UNESP), teve, também, em algumas fases do projeto, estudantes do curso de Biologia.

O exercício de reflexão com a comunidade, no grupo com os colegas e com as orientadoras, exigido pelas características do trabalho, permitiu aos estudantes de medicina transformarem suas concepções sobre a prática médica. A partir dessa experiência, pode-se dizer que foram quebrados alguns vínculos com o Modelo de Comunicação "Unilinear", aumentando as possibilidades de se exercer o que se chama de Modelo "dialógico", em que os indivíduos interagem compartilhando experiências, construindo novas relações de sentido no processo comunicacional, atuando, ambos os pólos, como "sujeitos" desse processo.

No cotidiano dos universitários, hoje na sua maioria médicos formados, essa experiência se refletiu em um redimensionamento das relações da prática profissional possibilitando viver uma relação menos normativa e mais construtivista: evitando falar "sobre" regras "para" o paciente, mas buscando um processo de construção de sentido "com" o paciente. Essas transformações influenciaram não 
somente a concepção de Educação em Saúde desse grupo, mas também a concepção da própria prática médica, identificando-se no processo dialógico uma outra possibilidade de se pensar o ato médico como um todo, não só no caráter educativo do ato, mas inclusive na avaliação clínica, tendo em vista que a dialogicidade possibilita um entendimento mais acurado do paciente no seu contexto psicológico, social e nas suas necessidades básicas.

Esta experiência possibilitou perceber alguns paradigmas que embasam a formação médica, na medida em que permitiu exercitar novos papéis, procurando compreender criticamente a condição de aprendiz e de professor. Para uma integrante do grupo de alfabetizadores, essa experiência representou a possibilidade de realizar um trabalho com a população em que "não se vai de médico". Médico aqui, no sentido restritivo da palavra, em sua função de curar especificamente a esfera biológica do indivíduo. E dessa experiência, algumas perguntas foram ganhando sentido. Será que práticas diferentes de nosso campo de formação práticas em que "não se vai de médico" aumentam as possibilidades de "desvendar" os paradigmas que nos referenciam e ver o mundo com mais clareza e, talvez, com mais crítica? Qual a importância para os estudantes de medicina de experiências fora do ambiente de trabalho médico?

Como aponta um dos universitários que integrou o projeto "não sabemos se teriam sido possíveis estas reflexões se procurássemos vivenciar um modelo alternativo de relacionamento no próprio modelo de saúde, já que estaríamos inseridos nos mesmos paradigmas assistencialistas. Sabemos, entretanto, que o que realmente foi decisivo não foi ter vivido simplesmente uma relação fora do ambiente medicalizado, mas sim, o processo de reflexão com o qual nos esforçamos para permear nossas práticas." Não se pode afirmar que, hoje, os estudantes que vivenciaram esta experiência são sempre democráticos em suas relações profissionais. Contudo, esses indivíduos buscam caminhar rumo a uma prática dialógica e, no mínimo, indignam-se com as relações de opressão freqüentes em nossa sociedade.

Esta experiência representa o caminho trilhado por um grupo de universitários que transformou não somente sua prática profissional mas também sua leitura do mundo.

Fábio Luiz Vieira ${ }^{1}$ Katrin Antonissen, Vanessa Moraes Assalim, Alessandra Pereira Silva, Valéria Cristina Yoshida ${ }^{2}$ Eliana Goldfarb Cyrino ${ }^{3}$ Maria Lúcia Toralles-Pereira ${ }^{4}$

\footnotetext{
${ }^{1}$ Estudante da Faculdade de Medicina de Botucatu, UNESP.

2 Médicas formadas pela Faculdade de Medicina de Botucatu, UNESP.

3 Orientadora do Projeto. Docente do Departamento de Saúde Pública da Faculdade de Medicina de Botucatu, UNESP.

${ }^{4}$ Orientadora do Projeto. Docente do Departamento de Educação do Instituto de Biociências de Botucatu, UNESP.
} 